\title{
Helminthic Infection in the Background of Active Pulmonary Tuberculosis: An Underreported Co- infection
}

\author{
Arshi Syal ${ }^{1}$, Yajur Arya ${ }^{1}$, Nikita N. Hapani ${ }^{1}$, Monica Gupta ${ }^{1}$, Saurabh Gaba ${ }^{1}$ \\ 1. Internal Medicine, Government Medical College and Hospital, Chandigarh, IND
}

Corresponding author: Monica Gupta, monicamanish2001@gmail.com

\begin{abstract}
Helminthic infections are widely prevalent in resource-poor countries. Tuberculosis, a disease contributing significantly to morbidity and mortality in endemic areas, often co-exists with helminthic infections. Poor living standards predispose to both of them. Moreover, untreated helminthic infection enhances the deleterious impact of tuberculosis, largely through immunological alteration. We are reporting the case of a 22 -year-old male who presented with a month-long history of abdominal pain, nausea, vomiting, fever and cough complicated by hemoptysis, along with an episode of the passage of a worm in the vomitus. A thorough workup revealed active pulmonary tuberculosis co-existing with intestinal ascariasis. Antihelminthic therapy was initiated along with anti-tubercular therapy, leading to significant improvement.
\end{abstract}

Categories: Internal Medicine, Infectious Disease, Pulmonology

Keywords: ascariasis, mebendazole, helminths, tuberculosis, pulmonary

\section{Introduction}

Helminthic infections are widespread in resource-poor countries. Their impact is further augmented with concurrent tuberculosis in the background. The co-existence of helminthic infections and tuberculosis is significant but is often underreported [1]. An overlapping initial complex of constitutional symptoms can lead to a delay in the diagnosis of a co-existent helminthic infection. Various risk factors increase the propensity as well as susceptibility for contracting these infections. Overcrowding and unhygienic living conditions predispose individuals to tuberculosis as well as helminthic infections. Factors including living in a rural area, consumption of vegetables and fruits without washing or peeling and having a body mass index (BMI) of less than $18.5 \mathrm{~kg} / \mathrm{m}^{2}$ have been significantly associated with an increased predisposition to intestinal helminthic infections [2]. A robust T-helper type 1 (Th1) response is required for resisting active tuberculosis infection. Helminths, on the other hand, induce a strong opposing T-helper type 2 (Th2) response along with total suppression of the immune system and preferential shift from the cell-mediated immune response toward humoral response [1]. These individuals are then predisposed to the development of active tuberculosis and suffer from increased morbidity. On the contrary, tuberculosis favors the immune escape of helminths, thereby propagating this vicious cycle [2].

Review began 03/01/2021 Review ended 03/06/2021 Published 03/06/2021

\section{() Copyright 2021}

Syal et al. This is an open access article distributed under the terms of the Creative Commons Attribution License CC-BY 4.0., which permits unrestricted use, distribution, and reproduction in any medium, provided the original author and source are credited.

\section{Case Presentation}

A 22-year-old male presented to the emergency room with hemoptysis. It was approximately $30 \mathrm{~mL}$ in volume and bright red in color. The episode occurred one hour prior to the presentation. It was not associated with any hypotension, dizziness, shortness of breath, history of prolonged immobility or recent surgery.

Two days prior to presentation, he had an episode of vomiting with the presence of a worm in vomitus. He also reported cough and fever for the preceding one month and a self-limiting episode of hemoptysis, approximately $15 \mathrm{~mL}$ in volume. The patient also complained of nausea and a vague, poorly localized central abdominal pain. Cough occurred in bouts and it was productive with straw-colored and mucoid sputum. There was history of intermittent fever, documented to be about 100-101 ${ }^{\circ} \mathrm{F}$, and evening rise of temperature associated with chills. There was no history of convulsions, the presence of any skin nodules or rash, any chronic ailment, contact with a patient of tuberculosis or previous anti-tubercular therapy (ATT) intake.

On initial evaluation, the patient was afebrile with a regular pulse rate of 95 per minute, blood pressure of $120 / 82 \mathrm{~mm}$ of $\mathrm{Hg}$, respiratory rate of 14 per minute and oxygen saturation of $96 \%$. His random blood sugar was $106 \mathrm{mg} / \mathrm{dL}$. A radiograph of the chest (Figure 1) revealed right upper zone opacity with a cavity along with bilateral areas of haziness. The blood counts, coagulogram, electrolytes, liver and renal function tests were unremarkable. 


\section{Cureus}

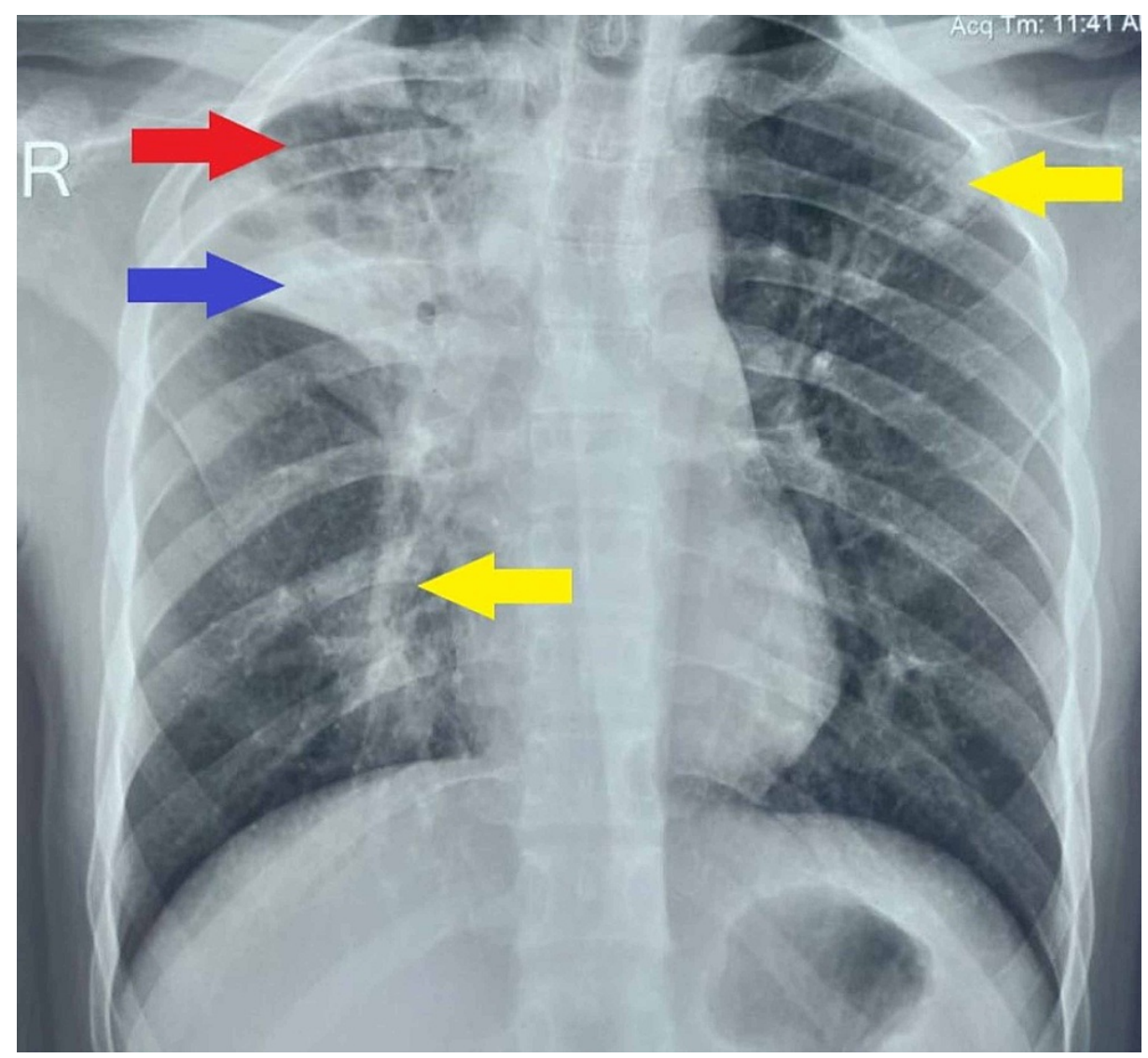

FIGURE 1: Radiograph of the chest showing a cavity (red arrow) and opacity (blue arrow) in the right upper zone along with bilateral areas of haziness (yellow arrows).

A diagnosis of ascariasis was made based on the examination of the worm (Figure 2). The patient was administered $100 \mathrm{mg}$ mebendazole orally, twice daily for three days. Microbiological investigations of sputum, including gram stain, potassium hydroxide $(\mathrm{KOH})$ stain for fungi and Ziehl-Neelsen (ZN) stain for acid-fast bacilli were negative on three occasions, and culture failed to detect any organism. A highresolution computed tomography (HRCT) scan of the chest (Figures $3 A, 3 B, 4 A, 4 B$ ) revealed a large patch of consolidation with central cavitation in the upper lobe of the right lung and bilateral multiple centrilobular nodules with linear branching (tree-in-bud sign). These changes were suggestive of an active tubercular infection. 


\section{Cureus}

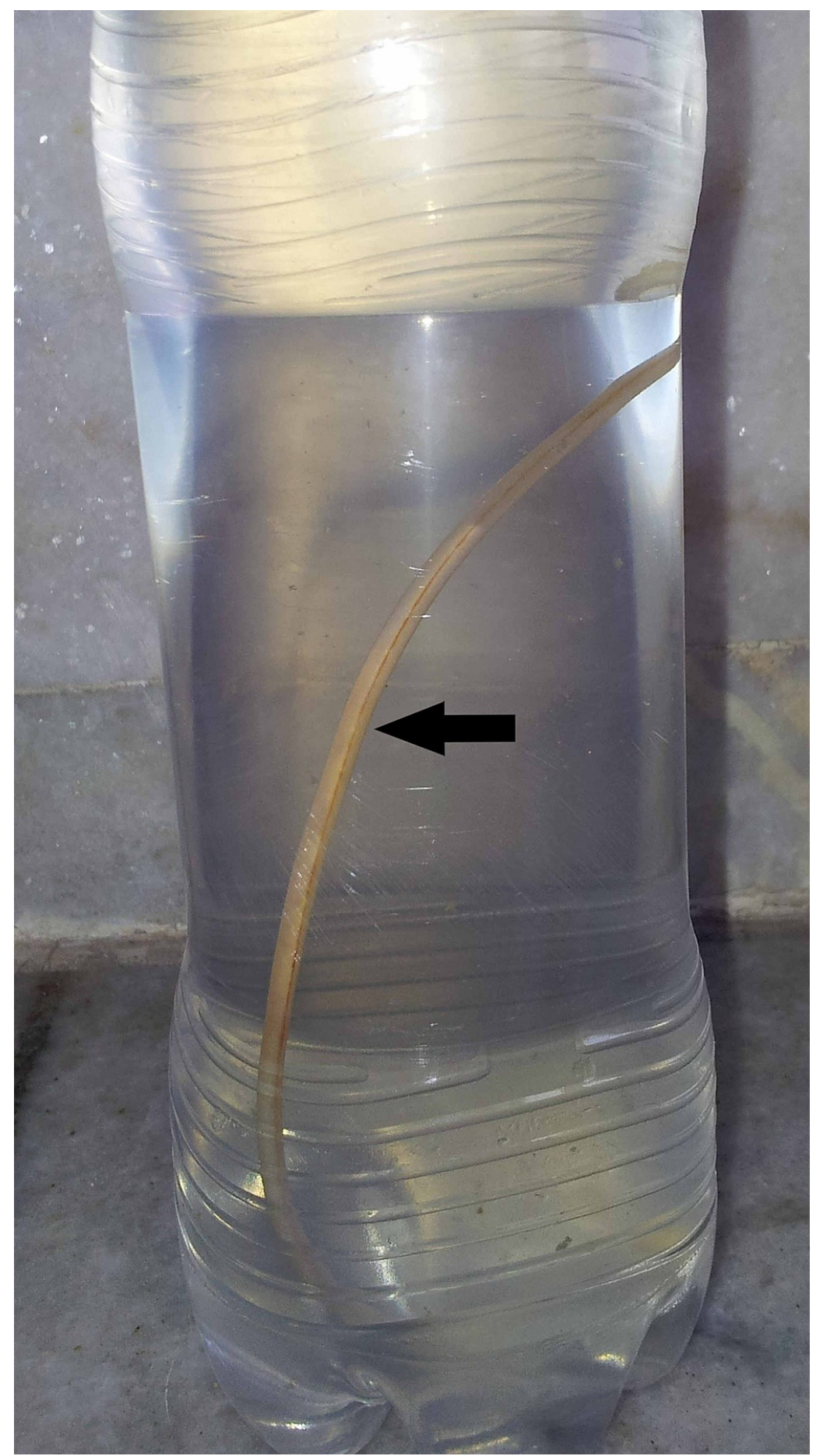

FIGURE 2: The worm (black arrow) that was present in the vomitus.

Gross examination revealed it to be Ascaris /umbricoides. It was approximately $25 \mathrm{~cm}$ in length, light pink in color and tapering at both ends. 


\section{Cureus}
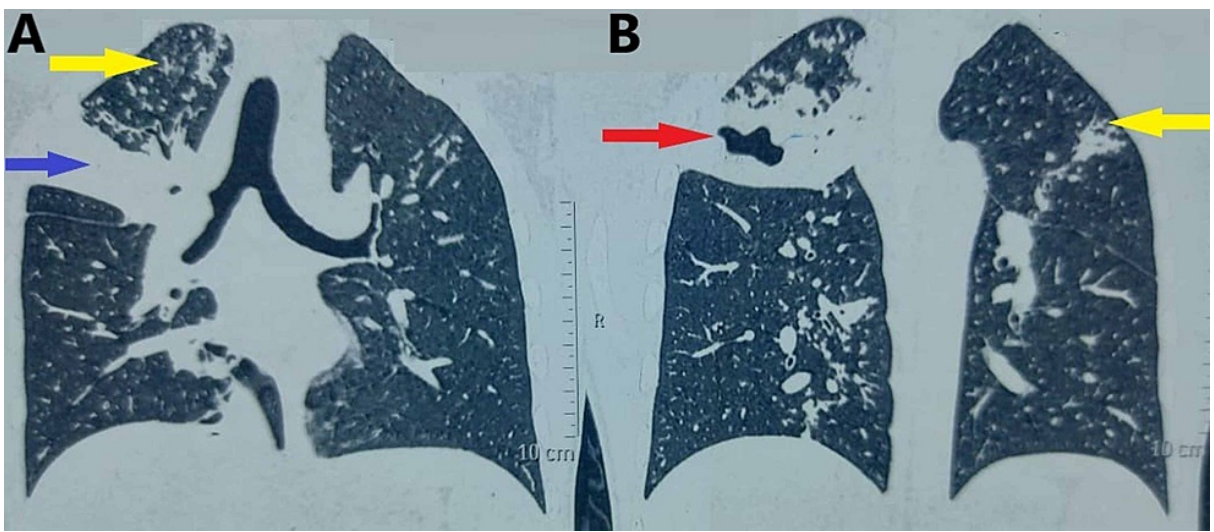

FIGURE 3: Coronal sections ( $A$ and $B$ ) of HRCT scan of the chest showing consolidation (blue arrow) and cavity (red arrow) in the right upper lobe along with bilateral branching centrilobular nodules (yellow arrows).

HRCT: High-resolution computed tomography

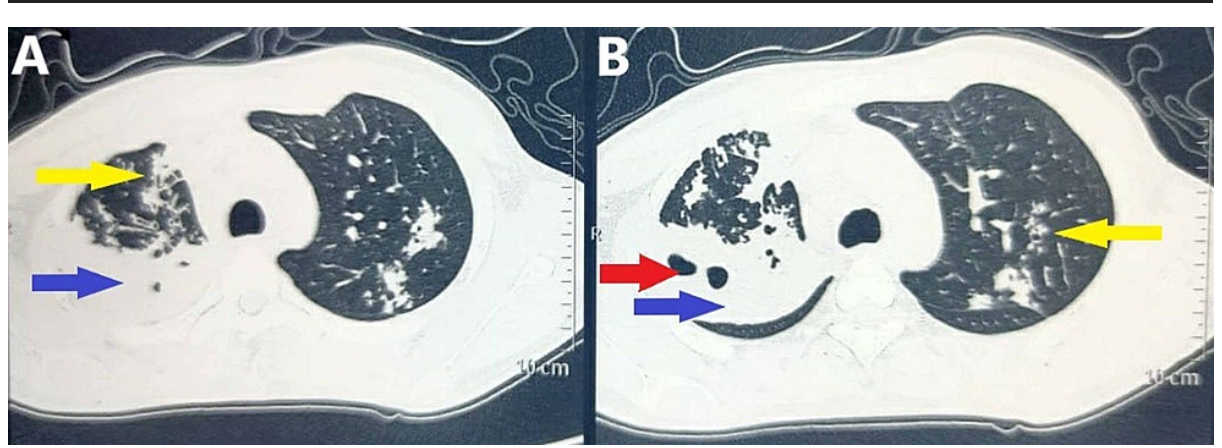

FIGURE 4: Axial sections ( $A$ and $B$ ) of HRCT scan of the chest showing consolidation (blue arrows) and cavity (red arrow) in the right upper lobe along with bilateral branching centrilobular nodules (yellow arrows).

HRCT: High-resolution computed tomography

A sputum cartridge-based nucleic acid amplification test (CBNAAT) was performed, which was positive for Mycobacterium tuberculosis and a diagnosis of active pulmonary tuberculosis was thus confirmed. Further management included initiation of a weight-based ATT regimen, comprising isoniazid, rifampicin, ethambutol and pyrazinamide along with pyridoxine supplementation. Routine monitoring of parameters including complete blood count, liver and renal function tests was performed. Symptomatic improvement started during the second week of ATT intake. He was discharged in a stable condition with continuation of ATT for a total duration of six months.

\section{Discussion}

The enhanced production of Th2 and T-regulatory cells along with consequential cytokine surge involving interleukins 4 and 10 with transforming growth factor-beta (TGF-beta) generated due to helminthic infection may be responsible for inhibition of Th1 response against M. tuberculosis. Co-infection with helminths can predispose toward the development of active M. tuberculosis infection, enhanced dissemination and development of sequelae [3]. The risk of development of active tuberculosis can be increased by as much as two-fold [4]. Also, increased generation of interleukin 10 and TGF-beta has been associated with the reactivation of latent tuberculosis [5]. Th2 upregulation is responsible for the enhanced production of mucus and collagen in an attempt to eliminate helminths. However, these mechanisms are not sufficient, often resulting in chronic infection [6]. Rather, activation of these mechanisms can surprisingly lead to the persistence of helminths consequential to immunological suppression by enhanced production of T-regulatory cells, a process that is further exaggerated by Th2 cells. Furthermore, Th2 cells 
lead to anergy of immunological cells, thereby compromising crucial cell-mediated immune response against $M$. tuberculosis [7].

Chronic infections can lead to anemia, growth retardation and impaired cognitive development. A BMI of less than $18 \mathrm{~kg} / \mathrm{m}^{2}$, involvement in raising poultry or livestock, having anemia and walking barefoot in farmlands are associated with intestinal helminthic infections [8]. Exposure to helminths during pregnancy is postulated to prime the neonate toward greater production of Th2 cells. This might be a factor leading to a lower Bacillus Calmette-Guerin (BCG) immunogenicity later in life [9]. Also, these infections might compromise the sensitivity of tuberculosis diagnostic tests by reducing interferon-gamma (IFN-gamma) levels [10].

Diagnosis of ascariasis is usually established by demonstration of eggs in feces or the adult worm in stool, vomitus or sputum. Anti-helminthic therapy forms the mainstay of treatment. Not only does this regimen eradicate helminths, but also reverses the altered IFN-gamma levels, thereby improving diagnostic sensitivity [11]. Benzimidazole class of antiparasitic agents is excellent therapeutic modalities. These drugs inhibit the polymerization of tubulin and microtubule-dependent glucose uptake in these parasites [12]. Albendazole (single oral dose of $400 \mathrm{mg}$ ) or mebendazole (single oral dose of $500 \mathrm{mg}$ or $100 \mathrm{mg}$ twice daily for three days) form the cornerstone of management in adult non-pregnant individuals, although it might not prevent reinfection [13]. Adverse effects like nausea, vomiting, abdominal pain and elevation of transaminases might occur, but it does not warrant cessation of therapy. Concurrent ATT administration for tuberculosis does not need to be withheld. Follow-up testing is usually not required but can be done by stool egg counts, approximately 14 days after therapy [14]. Strategies for control include improvements in sanitation, health education and mass anti-helminthic treatment [15]. Thus, taking a healthy and balanced diet, prevention of nutritional deficiencies and imparting education and creating awareness regarding personal hygiene are necessary to decrease the burden of helminthic infections in patients with tuberculosis.

\section{Conclusions}

Our case highlights the need to be cognizant of the possibility of co-existent helminthic and tubercular infections, especially in the high prevalence and resource-limited regions. An overlap in the clinical presentation of both of these conditions in the form of anorexia, fever, malaise and abdominal pain might lead to a delay in diagnosis. This delay should be avoided by suitable investigations in order to prevent an adverse clinical outcome. Anti-helminthic therapy forms the mainstay of management of ascariasis and ATT can be initiated concurrently.

\section{Additional Information \\ Disclosures}

Human subjects: Consent was obtained or waived by all participants in this study. Conflicts of interest: In compliance with the ICMJE uniform disclosure form, all authors declare the following: Payment/services info: All authors have declared that no financial support was received from any organization for the submitted work. Financial relationships: All authors have declared that they have no financial relationships at present or within the previous three years with any organizations that might have an interest in the submitted work. Other relationships: All authors have declared that there are no other relationships or activities that could appear to have influenced the submitted work.

\section{References}

1. Cadmus SI, Akinseye VO, Taiwo BO, Pinelli EO, van Soolingen D, Rhodes SG: Interactions between helminths and tuberculosis infections: implications for tuberculosis diagnosis and vaccination in Africa. PLoS Negl Trop Dis. 2020, 14:0008069. 10.1371/journal.pntd.0008069

2. Alemu G, Mama M: Intestinal helminth co-infection and associated factors among tuberculosis patients in Arba Minch, Ethiopia. BMC Infect Dis. 2017, 17:68. 10.1186/s12879-017-2195-1

3. Rook GA: Th2 cytokines in susceptibility to tuberculosis . Curr Mol Med. 2007, 7:327-37. $10.2174 / 156652407780598557$

4. Elias D, Mengistu G, Akuffo H, Britton S: Are intestinal helminths risk factors for developing active tuberculosis?. Trop Med Int Health. 2006, 11:551-8. 10.1111/j.1365-3156.2006.01578.x

5. Ribeiro-Rodrigues R, Resende Co T, Rojas R, et al.: A role for $\mathrm{CD} 4+\mathrm{CD} 25+\mathrm{T}$ cells in regulation of the immune response during human tuberculosis. Clin Exp Immunol. 2006, 144:25-34. 10.1111/j.13652249.2006.03027.x

6. Ottenhoff TH, Kumararatne D, Casanova JL: Novel human immunodeficiencies reveal the essential role of type-I cytokines in immunity to intracellular bacteria. Immunol Today. 1998, 19:491-4. 10.1016/s01675699(98)01321-8

7. Borkow G, Leng Q, Weisman Z, Stein M, Galai N, Kalinkovich A, Bentwich Z: Chronic immune activation associated with intestinal helminth infections results in impaired signal transduction and anergy. J Clin Invest. 2000, 106:1053-60. 10.1172/JCI10182

8. Li XX, Chen JX, Wang LX, et al.: Prevalence and risk factors of intestinal protozoan and helminth infections among pulmonary tuberculosis patients without HIV infection in a rural county in P. R. China. Acta Trop. 2015, 149:19-26. 10.1016/j.actatropica.2015.05.001

9. Elias D, Akuffo H, Pawlowski A, Haile M, Schön T, Britton S: Schistosoma mansoni infection reduces the 


\section{Cureus}

protective efficacy of BCG vaccination against virulent Mycobacterium tuberculosis. Vaccine. 2005, 23:132634. 10.1016/j.vaccine.2004.09.038

10. Thomas TA, Mondal D, Noor Z, et al.: Malnutrition and helminth infection affect performance of an interferon gamma-release assay. Pediatrics. 2010, 126:1522-9. 10.1542/peds.2010-0885

11. Anuradha R, Munisankar S, Bhootra Y, Dolla C, Kumaran P, Nutman TB, Babu S: Anthelmintic therapy modifies the systemic and mycobacterial antigen-stimulated cytokine profile in helminth-latent Mycobacterium tuberculosis coinfection. Infect Immun. 2017, 85:00973-16. 10.1128/IAI.00973-16

12. Lacey E: Mode of action of benzimidazoles. Parasitol Today. 1990, 6:112-5. 10.1016/0169-4758(90)90227-u

13. Conterno LO, Turchi MD, Corrêa I, Monteiro de Barros Almeida RA: Anthelmintic drugs for treating ascariasis. Cochrane Database Syst Rev. 2020, 4:CD010599. 10.1002/14651858.CD010599.pub2

14. Levecke B, Easton AV, Cools P, et al.: The optimal timing of post-treatment sampling for the assessment of anthelminthic drug efficacy against Ascaris infections in humans. Int J Parasitol Drugs Drug Resist. 2018, 8:67-9. 10.1016/j.ijpddr.2017.12.004

15. Dold C, Holland CV: Ascaris and ascariasis. Microbes Infect. 2011, 13:632-7. 10.1016/j.micinf.2010.09.012 